\title{
Continuous prefabricated cross-beams manufactured by using off-shuttering molding technologies
}

\author{
Anatoliy Prokopovich ${ }^{1,}$, Vladimir Repekto ${ }^{1}$, and Andrey Aleshin ${ }^{1}$ \\ ${ }^{1}$ Samara State Technical University, Academy of Architecture and Civil Engineering, \\ Molodogvardeyskaya St., 194, Samara, 443001, Russia
}

\begin{abstract}
The paper describes a new constructive solution of prefabricated cross-beams manufactured be using off-shuttering molding technologies. Prefabricated elements of such cross-beams are pre-stressed trough-shaped parts. Together with hollow slab panels, stacked on the upper surfaces of their vertical walls, they serve as permanent shuttering for installing required crosswise and longitudinal (for support moments) reinforcement and for further pouring of cast concrete. The study provides a methodology and gives tests results of three series of prototype samples and of one full-sized prefabricated cross-beam. The purpose of the tests is to study the actual work of prefabricated cross-beams of the proposed construction. To analyze the test results, the authors performed check calculations of prototype samples according to the existing Russian design regulations of reinforced concrete structures. The obtained data analysis leads to a conclusion that the proposed construction of prefabricated crossbeams is quite reliable and makes it possible to give recommendations on their calculation and design.
\end{abstract}

\section{Introduction}

Now in Russia there are large-scale processes of the technical re-equipment of enterprises producing reinforced concrete structures. Among the most dynamically introduced technologies, it is possible to distinguish the off shuttering molding technology [1], which makes it possible to produce various designs of constant cross-section length, reinforced with pre-stressed high-strength reinforcement. In this case, the cross-section can be of almost any shape (rectangular, T-shaped, I-shaped, U-shaped, with and without pinholes, etc.), and the product length is limited only by the requirements for the load bearing capacity of the manufactured structure. The authors proposed the construction of precast reinforced concrete frame, where in addition to hollow-core slabs manufactured by the off shuttering molding technology with continuous precast crossbeams [2], precast parts of which are manufactured as hollow-core slabs according to off shuttering molding technology, unlike cross beams for a similar frame, considered in the paper [3] and manufactured by conveyor technology. An example of the use of beams of T-section,

* Corresponding author: Prokopovich@inbox.ru 
manufactured by the off shuttering molding technology, can be the construction of a precast cross beam, mentioned above [4].

The proposed crossbeam (Figure 1) consists of pre-stressed concrete parts with complex geometric shape, installed between the columns, and monolithic concrete which combines prefabricated elements (columns and beam parts) into a continuous single precast monolithic structure. Thus, the part and the slabs stacked on it serve as permanent shuttering for concrete, the part being a kind of pre stressed reinforcing element. To prevent the concrete from flowing into the slab pinholes plugs are inserted. Span parts in the proposed precast cross beam are taken up by the longitudinal pre stressed reinforcement part. For the take up of support elements in the nearby zone, the upper non-tensioning longitudinal reinforcement passing through the column (Figure 5) is installed. The shearing strains are taken by the vertical reinforcing bars of frames. When the span poi4-4nts obtained from the results of static analysis framework, exceed the maximum cross beam strength, and the cross beam is reinforced only by pre stressed reinforcement parts on the bottom part (before laying monolithic concrete) additional untensioned longitudinal reinforcement can be set.

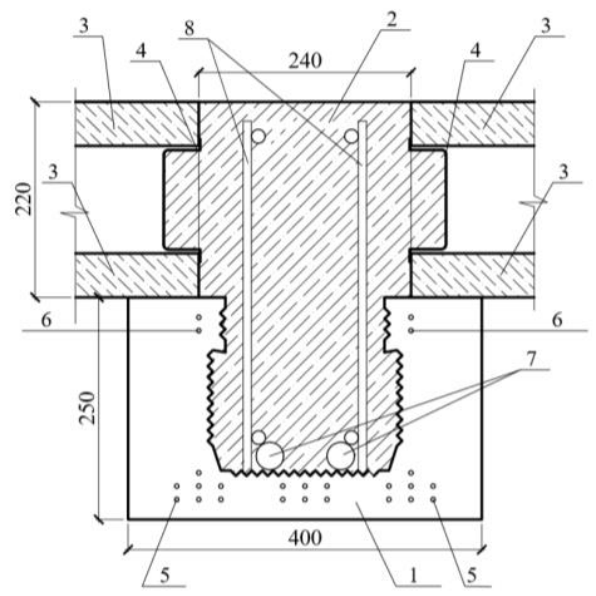

Fig. 1. Cross beam section in the part of the span.

1 - prefabricated beam part; 2 - monolithic concrete; 3 - hollow-core plank; 4 - plastic plug; 5, 6 lower and upper pre-reinforced wire reinforcement with $5 \mathrm{~mm}$ diameter, carbon steel wire for reinforcement (Russian standards - Bp1400: 7) - additional (if needed) lower untensioned reinforcement A400: 8 - reinforcement frames from A400 cores.

\section{Materials and methods}

In order to study the function and destruction nature of the proposed precast cross beams and prefabricated pretension part acting as an independent structure, as well as to study their strength in normal and inclined cross sections, special actual size prototype samples were manufactured and tested. The three series of samples were made and tested (two samples of the first series and three samples of the second and third series) and a cross beam part. Before the tests, the actual strength of concrete of each sample was determined by the methods of destructive and non-destructive testing (model N Schmidt hammer) (in cubes 100x100x100 mm).

The main geometric characteristics of the samples are shown in Figures 2 and 3, and the reinforcement parameters and strength characteristics of the concrete in the samples in Table 1. 
a)

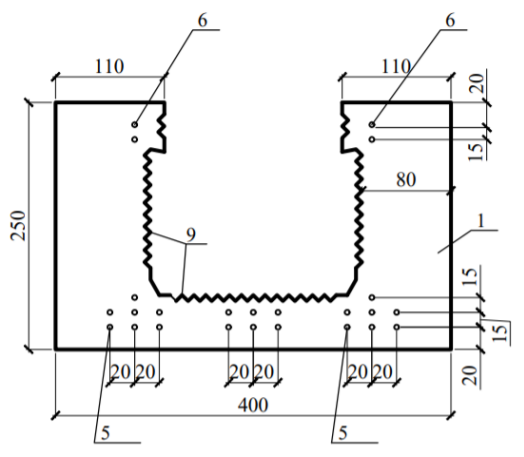

б)

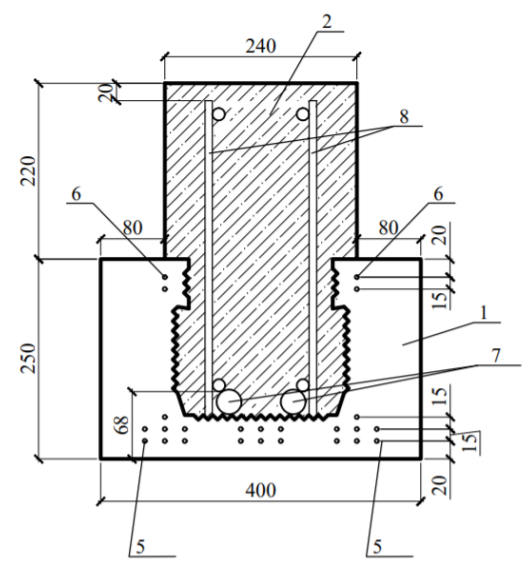

Fig. 2. The cross beams section (a) and the first series samples (b).

1 - the prefabricated cross beam part; 2 - monolithic concrete; 3 - hollow core slab; 4 - plastic plug; 5 , 6 - lower and upper pre-reinforced wire reinforcement with $5 \mathrm{~mm}$ diameter, carbon steel wire for reinforcement (Russian standards - Bp1400: 7) - additional (if needed) lower A400: 8 reinforcement frames from A400 cores.

The test load for all samples was applied in steps up to destruction with an exposure time of 10 minutes at each stage. In the process of testing, the observation of the appearance and development of normal, inclined and contact cracks was made (between the beam part and monolithic concrete). The deflection in the middle of the span and the drafts of the supports were measured by the PAO-6 flexometers, the deformation of the concrete by resistance strain gages with a base of $50 \mathrm{~mm}$ and the Hugenberger strainmeters with a base of 100 $\mathrm{mm}$, deformation of the reinforcemen by strain gages with a base of $10 \mathrm{~mm}$.

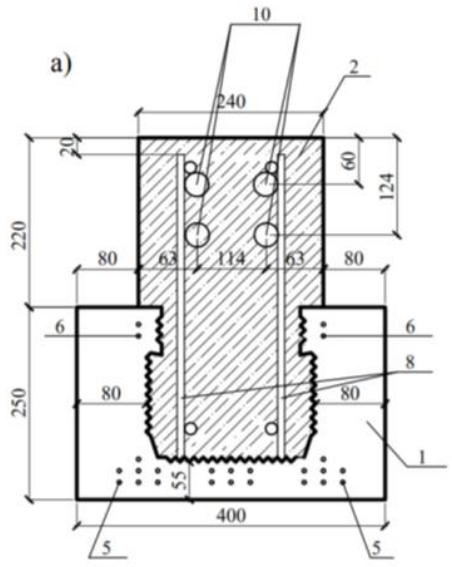

б)

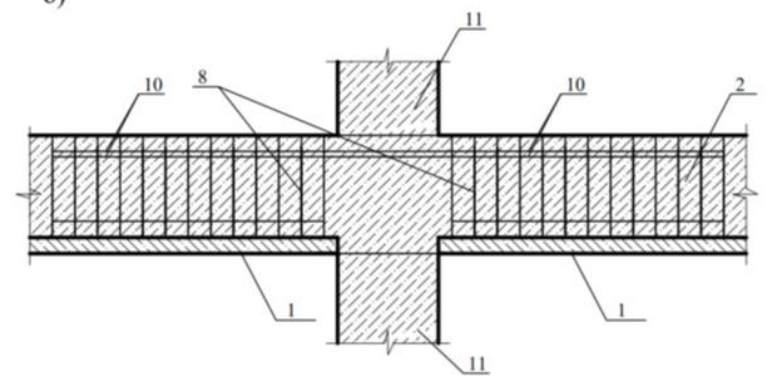

Fig. 3. Cross beam cross-section (a) and longitudinal (b) section of prototype samples of the second and third series.

1 - the prefabricated cross beam part; 2 - monolithic concrete; 3 - hollow core slab; 4 - plastic plug; 5 , 6 - lower and upper pre-reinforced wire reinforcement with $5 \mathrm{~mm}$ diameter, carbon steel wire for reinforcement (Russian standards - Bp1400: 7) - additional (if needed) lower A400: 8 reinforcement frames from A400 cores.

Samples of the first series (Figure 2) and prefabricated pre-stressed cross beam part were intended for studying the nature of their operation in the flexural elements and they were 
tested according to the scheme of the free-run single-span beam (Figure 4). The load $\mathrm{N}^{0}$ was created by a hydraulic cell and through the system the lifting beams was transferred to the samples in the form of eight concentrated forces applied to the shelves of the precast

Table 1. Parameters of reinforcement and strength characteristics of concrete in samples

\begin{tabular}{|c|c|c|c|c|c|c|c|c|c|c|c|c|}
\hline \multirow{3}{*}{$\begin{array}{c}\mathrm{Se} \\
\text { rie } \\
\mathrm{S}\end{array}$} & \multirow{3}{*}{$\begin{array}{l}\text { Sample } \\
\text { code }\end{array}$} & \multirow{3}{*}{$\begin{array}{l}\mathrm{A}_{\mathrm{sp}} \\
\mathrm{cm}^{2}\end{array}$} & \multirow{3}{*}{$\begin{array}{l}\mathrm{a}_{\mathrm{sp}} \\
\mathrm{cm}\end{array}$} & \multirow{3}{*}{$\begin{array}{l}\mathrm{A}_{\mathrm{sp}}^{\prime} \\
\mathrm{cm}^{2}\end{array}$} & \multirow{3}{*}{$\begin{array}{l}\mathrm{a}_{\mathrm{sp}} \\
\mathrm{cm}\end{array}$} & \multirow{3}{*}{$\begin{array}{l}\mathrm{A}_{\mathrm{s}} \\
\mathrm{cm}^{2}\end{array}$} & \multirow{3}{*}{$\begin{array}{l}\mathrm{a}_{\mathrm{s}} \\
\mathrm{cm}\end{array}$} & \multirow{3}{*}{$\begin{array}{c}\mathrm{q}_{\mathrm{sw}} \\
\mathrm{kN} / \mathrm{cm}\end{array}$} & \multicolumn{4}{|c|}{$\begin{array}{l}\text { The actual average strength } \\
\text { of concrete samples }\end{array}$} \\
\hline & & & & & & & & & \multicolumn{2}{|c|}{$\begin{array}{c}\text { for beams } \\
\text { parts }\end{array}$} & \multicolumn{2}{|c|}{$\begin{array}{c}\text { for concrete } \\
\text { grouting }\end{array}$} \\
\hline & & & & & & & & & $\begin{array}{l}\mathrm{R}_{\mathrm{bm}} \\
\mathrm{MPa}\end{array}$ & $\begin{array}{l}\mathrm{R}_{\mathrm{btm}} \\
\mathrm{MPa}\end{array}$ & 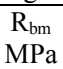 & $\begin{array}{l}\mathrm{R}_{\text {bnm }} \\
\mathrm{MPa}\end{array}$ \\
\hline 1 & 2 & 3 & & 5 & 6 & 7 & 8 & 9 & 10 & 11 & 12 & 13 \\
\hline & part & 3.92 & \multirow[t]{2}{*}{3.0} & \multirow{9}{*}{0.78} & \multirow{9}{*}{2.75} & - & - & - & 34.1 & 3.0 & - & - \\
\hline 1 & $1-1-400$ & 3.92 & & & & 9.8 & 7.0 & 394 & 35.0 & 3.0 & 21.7 & 2.2 \\
\hline & $1-2-310$ & 3.53 & 3.5 & & & - & - & 590 & 34.1 & 2.9 & 28.0 & 2.6 \\
\hline 2 & $2-1-400$ & 3.92 & \multirow{5}{*}{3.0} & & & 32.2 & 13.7 & 394 & 34.6 & 3.0 & 28.1 & 2.6 \\
\hline & $2-2-400$ & 3.92 & & & & 32.2 & 11.3 & 394 & 34.3 & 3.0 & 28.9 & 2.7 \\
\hline & $2-3-400$ & & & & & 32.2 & 9.5 & 394 & 34.0 & 3.0 & 20.0 & 2.1 \\
\hline \multirow[t]{3}{*}{3} & $3-1-400$ & 3.92 & & & & 32.2 & 11.1 & 590 & 35.0 & 3.1 & 22.1 & 2.2 \\
\hline & $3-2-400$ & & & & & 32.2 & 9.7 & 590 & 34.6 & 3.0 & 21.6 & 2.2 \\
\hline & $3-3-310$ & 3.53 & 3.5 & & & 32.2 & 11.7 & 590 & $\begin{array}{l}34.8 \\
\end{array}$ & 3.0 & 26.5 & 2.5 \\
\hline
\end{tabular}

Notations adopted in Table 1:

$\mathrm{A}_{\mathrm{sp}}$ - the cross-sectional area of the lower pre stressed reinforcement of the cross beam part; $\mathrm{a}_{\mathrm{sp}}$ - the distance from the center of gravity of the $A_{\mathrm{sp}}$ reinforcement to the bottom surface of the cross beam part; $A_{s}$ - the cross-sectional area of an unstressed stretched reinforcement (the lower in the span, the upper on the support); $a_{s}$ - the distance from the center of gravity of the reinforcement $A_{s}$ of the cross beam to its nearest horizontal side; $\mathrm{q}_{\mathrm{sw}}$ - the force in the clamps per unit length, determined by formula (8.59) [3], replacing $\mathrm{R}_{\mathrm{sw}}$ by $0.8 * \mathrm{R}_{\mathrm{sn}}$, where $\mathrm{R}_{\mathrm{sn}}=400 \mathrm{MPa}$ - the standard value of the resistance of reinforcement class $A 400 ; R_{b m}, R_{b t m}$ - the average strength of concrete to axial compression and axial tension, respectively, taken as a result of determining the actual strength of concrete samples.

crossbeams and when testing the crossbeam part at the top of its edges. The distance between the supports of the upper distributor beam is $1600 \mathrm{~mm}$, the two lower ones - 600 $\mathrm{mm}$ each, the calculated span of the samples and the beam part were taken equal to 6850 $\mathrm{mm}$.

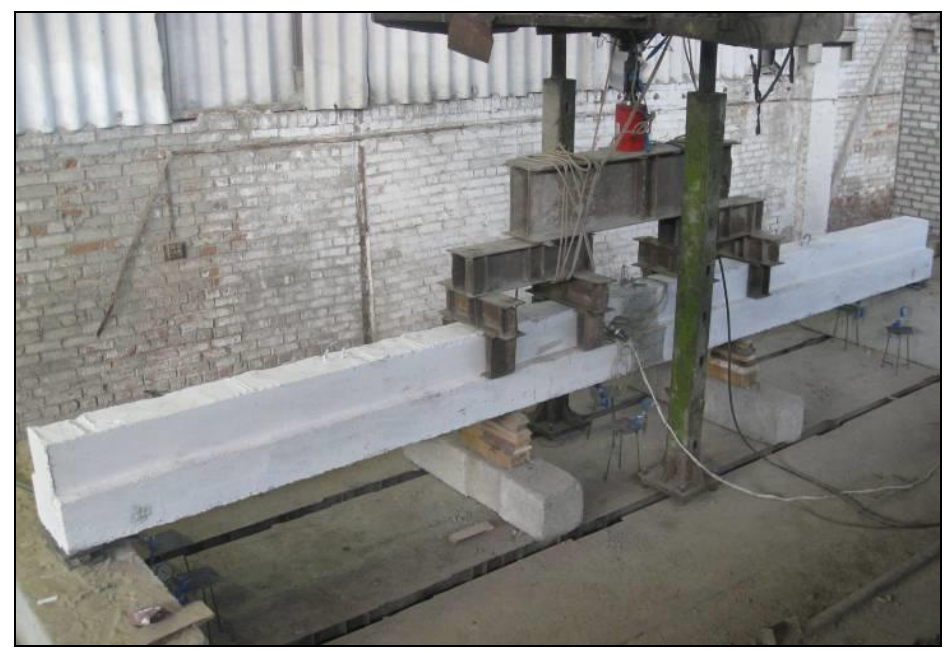

Fig. 4. General view of the test console for the first series samples of the cross beam parts. 
Samples of the second and third series were intended to study the operation of the precast cross-beam in the joint zone with the column, with maximum shearing force and the reference torque. They were made of column fragments $1.4 \mathrm{~m}$ high and $1.4 \mathrm{~m}$ pre-stressed parts (Figure 3), connected by monolithic concrete and tested using a cantilever scheme (Figure 5). Load $\mathrm{N}^{0}$ was created by a hydraulic jack and transmitted directly to one of the consoles. The opposite console was fixed from vertical displacements in a place symmetrical to the place where the load $\mathrm{N}^{0}$ was applied. The places of application of the load and the consoles fastening when testing of the samples of 2-d series are chosen in such a way that the samples destruction occurs from the action of the supporting zone and the samples of the 3-d series - from the action of shearing force. The distance from the column side to the center of application of the force $\mathrm{N}^{0}$ for the samples of the second series was 1.3 $\mathrm{m}$, and for the samples of the third series $-1.0 \mathrm{~m}$.

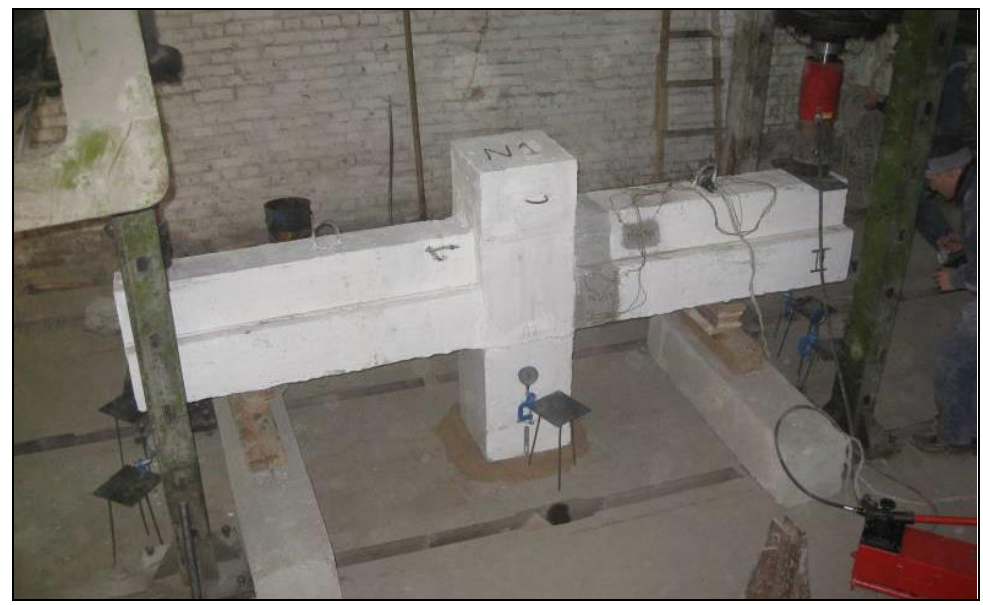

Fig. 5. General view of the test console for the 2-d and 3-d series.

\section{Results}

The cross beam parts test results. The first normal cracks in the part appeared in the middle of the span in the lower zone at a load of $\mathrm{N}^{0}=4.2$ tons $(60 \%$ of the fracture). The width of the crack was $0.05 \mathrm{~mm}$, the height of crack propagation from the lower face was $50-80 \mathrm{~mm}$, the average distance between the cracks along the length of the part was $250 \mathrm{~mm}$, the deflection in the middle of the span was $18.4 \mathrm{~mm}$. With gradual load increasing, there was the development of existing cracks and the formation of new normal ones occurred between the initially formed cracks, with an average crack pitch of $125 \mathrm{~mm}$. At a load of 6 tons ( $85.7 \%$ of the destructive one), the width of crack opening reached $0.3 \mathrm{~mm}$, and the deflection in the middle of the span was $57.4 \mathrm{~mm}$. At a load of $\mathrm{N}^{0}{ }_{\mathrm{u}}=7 \mathrm{t}$, there was a brittle sample fracture in the middle zone over the compressed concrete.

\subsection{The results of the first series samples testing}

The sample 1-1-400. The destruction of the sample occurred at a load of $\mathrm{N}^{0}{ }_{\mathrm{u}}=270 \mathrm{kN}$ in compressed concrete in the cross section in the middle of the span. At a load of $140 \mathrm{kN}$ (51.7\% of the destructive), in the middle of the span in the lower stretched zone, the first normal cracks appeared with a width disclosure of $0.2 \mathrm{~mm}$ to a height of $50-85 \mathrm{~mm}$. The distance between the cracks along the length of the specimen was $250 \mathrm{~mm}$. Under this load, the deflection in the middle of the span was $7.8 \mathrm{~mm}$. Later, the existing cracks and the formation of new normal cracks between the existing ones took place, with the minimum 
crack pitch being $125 \mathrm{~mm}$, and the height development did not exceed $250 \mathrm{~mm}$ (ie, normal cracks did not develop into the upper monolithic part). With a load close to destructive one, the width of crack opening reached $0.2-0.4 \mathrm{~mm}$, the deflection in the middle of the span was $32.8 \mathrm{~mm}$. It should be noted that during the test of the sample there was no cracking between the beam part and monolithic concrete.

Sample 1-2-310. The sample destruction occurred with compressed concrete at a load of $\mathrm{N}^{0}{ }_{\mathrm{u}}=170 \mathrm{kN}$. Under the load of $9 \mathrm{kN}(52.9 \%$ of the destructive), in the middle of the span in the stretched zone, the first normal cracks appeared with a $0.2 \mathrm{~mm}$ wide opening to a height of 50-85 mm. The distance between the cracks along the length of the specimen was $250 \mathrm{~mm}$. The deflection in the middle of the span was $12.7 \mathrm{~mm}$. Later, the existing and the formation of new normal cracks took place, with the minimum crack pitch being $125 \mathrm{~mm}$, and the height development did not exceed $250 \mathrm{~mm}$ (that is, the formed normal cracks did not spread to the upper monolithic part and the height development did not exceed 250 $\mathrm{mm})$. Under the load of $15 \mathrm{kN}$ ( $88.2 \%$ of the destructive), the crack opening was up to 0.3 $\mathrm{mm}$, the deflection in the middle of the span was $38 \mathrm{~mm}$. As in the previous sample, the formation of cracks between the beam part and monolithic concrete did not occur.

\subsection{The results of the second series samples testing}

Sample 2-1-400. The sample destruction occurred under the load of $\mathrm{N}_{\mathrm{u}}^{0}=310 \mathrm{kN}$ due to the yield strength of the upper longitudinal reinforcement, and was accompanied by a significant opening of the normal crack at the side of the column, followed by concrete crushing of the part.

The sample 2-2-400 collapsed under the load of $\mathrm{N}^{0}{ }_{\mathrm{u}}=353 \mathrm{kN}$ due to the yield strength of the upper longitudinal reinforcement, accompanied by a significant opening of the normal crack at the column side, followed by concrete part crushing. In this case, the concrete of the monolithic part over the upper longitudinal reinforcement was destroyed, indicating the disruption of the adhesion between the upper stretched longitudinal reinforcement and the monolithic concrete.

The sample 2-3-400 was destroyed under the load of $\mathrm{N}^{0}{ }_{\mathrm{u}}=329 \mathrm{kN}$. The destruction nature (Figure 6) was different from the previous two. By the time of destruction in the sample, a sharp increase in the width of the inclined cracks occurred, followed by concrete crushing in the middle zone of the upper monolithic part. More over the monolithic concrete was destroyed over the upper working armature.

\subsection{The results of the third series samples testing}

Sample 3-1-400. The sample destruction occurred under the load of $\mathrm{N}_{\mathrm{u}}^{0}=365 \mathrm{kN}$. Sample 3-2-400. The sample destruction occurred under the load of $\mathrm{N}_{\mathrm{u}}^{0}=370 \mathrm{kN}$. Sample 3-3-310. Destruction of the sample occurred under the load of $\mathrm{N}_{\mathrm{u}}^{0}=300 \mathrm{kN}$. When the destructive loads were reached in all the samples of the third series, the inclined cracks were sharply opened, followed by the destruction of the concrete of the cross beam part (Figure 7). By nature, it is a typical destruction on concrete strips between inclined cracks.

\section{Discussion}

The results of tests and check calculations for all samples are presented in Table 2. The check calculations of the tested prefabricated cross beams for determining theoretical destructive loads as well as comparing them with experimental values are performed both for reinforced concrete $\mathrm{T}$-sections in accordance with hardening tests $8.1 .8 \div 8.1 .13$ and 8.1.32, 8.1.33 [5] with the replacement of the calculated resistances of concrete to the corresponding average values, and the calculated resistances of the reinforcement to the corresponding normative values. 
Analysis of the data given in Table 2 shows that the calculation of the strength of normal sections of a precast cross beams can be carried out with sufficient reliability by the

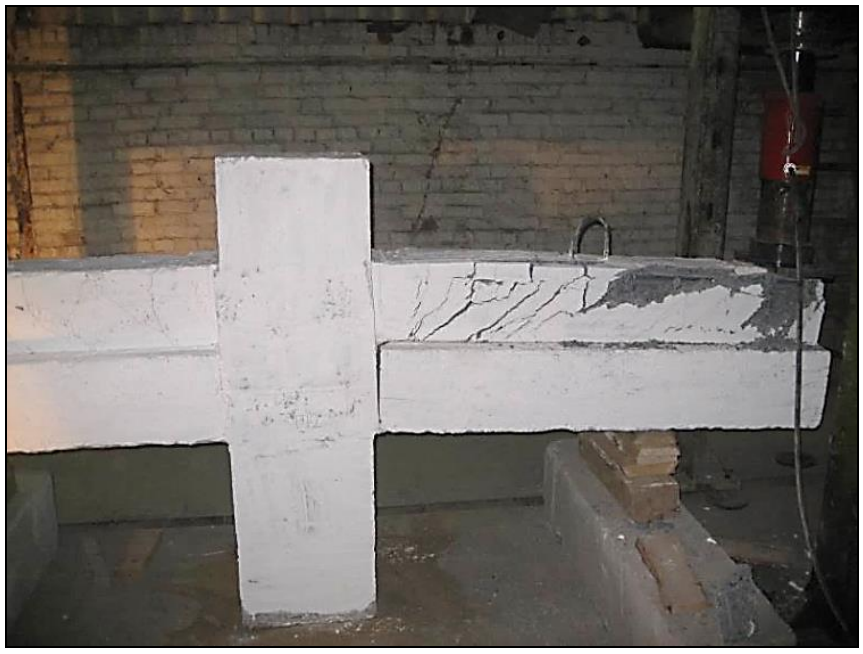

Fig. 6. The third sample of the second series under the load of 35,1 tons ( $99 \%$ of the destructive).

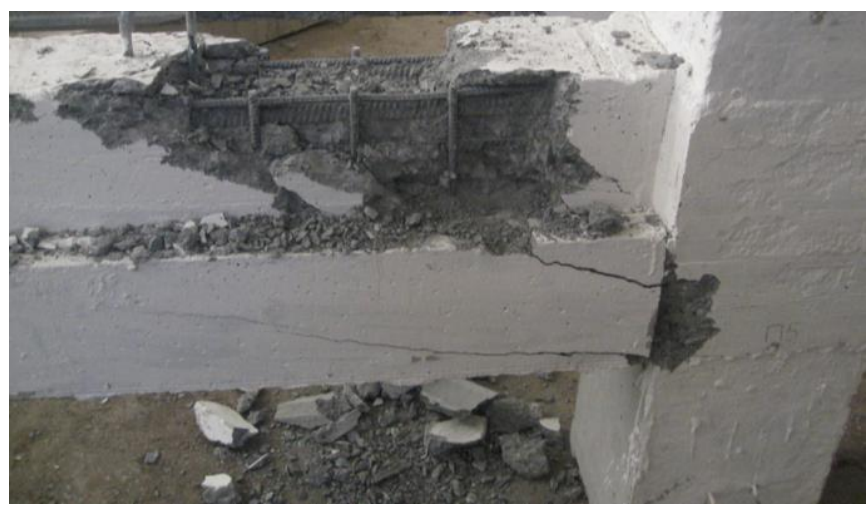

Fig. 7. Characteristic destruction of samples of the third series from the action of transverse force.

Table 2. Results of tests and check calculations of prototype samples

\begin{tabular}{|c|c|c|c|c|c|c|c|c|c|c|c|}
\hline \multirow{2}{*}{$\begin{array}{c}\mathrm{Se} \\
\text { rie } \\
\mathrm{S}\end{array}$} & \multirow[t]{2}{*}{$\begin{array}{c}\text { Sample } \\
\text { code }\end{array}$} & \multicolumn{3}{|c|}{$\begin{array}{c}\text { Experimental values of } \\
\text { destructive load }\left(\mathrm{N}^{0} \mathrm{u}\right) \text { and } \\
\text { destructive forces }\left(\mathrm{M}_{\mathrm{u}}^{0} \text { и }\right. \\
\left.\mathrm{Q}_{\mathrm{u}}^{0}\right)\end{array}$} & \multicolumn{5}{|c|}{$\begin{array}{l}\text { Theoretic values of destructive forces }\left(\mathrm{M}_{\mathrm{u}},\right. \\
\left.\qquad \mathrm{Q}_{\text {mu}}, \mathrm{Q}_{\text {bu }}, \mathrm{Q}_{\text {swu }}, \mathrm{Q}_{\mathrm{u}}\right)\end{array}$} & \multirow{2}{*}{$\frac{\mathrm{M}_{\mathrm{u}}^{0}}{\overline{\mathrm{M}}_{\mathrm{u}}}$} & \multirow{2}{*}{$\frac{\mathrm{Q}^{0}{ }_{\mathrm{u}}}{\mathrm{Q}_{\mathrm{u}}}$} \\
\hline & & $\begin{array}{l}\mathrm{N}_{\mathrm{u}}^{0} \\
\mathrm{kN}\end{array}$ & $\begin{array}{c}\mathrm{M}^{0}{ }_{u} \\
\mathrm{kN}^{*} * \mathrm{~m}\end{array}$ & $\begin{array}{l}\mathrm{Q}_{\mathrm{u}}^{0} \\
\mathrm{kN}\end{array}$ & $\begin{array}{c}\mathrm{M}_{\mathrm{u}} \\
\mathrm{kN*m}\end{array}$ & $\begin{array}{l}\mathrm{Q}_{\text {пu }} \\
\mathrm{kN}\end{array}$ & $\begin{array}{l}\mathrm{Qbu} \\
\mathrm{kN}\end{array}$ & $\begin{array}{l}\text { Qswu } \\
\mathrm{kN}\end{array}$ & $\begin{array}{c}\mathrm{Qu} \\
\mathrm{kN}\end{array}$ & & \\
\hline \multirow[t]{2}{*}{1} & 2 & 3 & 4 & 5 & 6 & 7 & 8 & 9 & 10 & 11 & 12 \\
\hline & Part & 70 & 91 & 35 & - & - & - & - & - & - & - \\
\hline \multirow[t]{2}{*}{1} & $1-1-400$ & 270 & 354 & 135 & 343 & - & - & - & - & 1.03 & - \\
\hline & $1-2-310$ & 170 & 223 & 85 & 189 & - & - & - & - & 1.18 & - \\
\hline \multirow[t]{3}{*}{2} & $2-1-400$ & 310 & 403 & 310 & 373 & 719 & 336 & 115 & 451 & 1.09 & - \\
\hline & $2-2-400$ & 353 & 459 & 353 & 404 & 739 & 343 & 115 & 458 & 1.15 & - \\
\hline & $2-3-400$ & 329 & 428 & 329 & 421 & 511 & 263 & 115 & 378 & 1.03 & 0.64 \\
\hline \multirow[t]{3}{*}{3} & $3-1-400$ & 365 & 365 & 365 & 404 & 564 & 283 & 173 & 456 & 1.19 & 0.65 \\
\hline & $3-2-400$ & 370 & 370 & 370 & 424 & 551 & 279 & 173 & 452 & 1.14 & 0.67 \\
\hline & $3-3-310$ & 300 & 300 & 300 & 383 & 423 & 201 & 173 & 374 & 1.03 & 0.71 \\
\hline
\end{tabular}


Notations adopted in Table 1:

$\mathrm{N}^{0}{ }_{\mathrm{u}}, \mathrm{M}_{\mathrm{u}}^{0}, \mathrm{Q}_{\mathrm{u}}^{0}$ are the experimental values of the destructive load on the samples and the corresponding forces (the middle of the span or in the console grip and transverse force), respectively; $\mathrm{M}_{\mathrm{u}}, \mathrm{Q}_{\mathrm{pu}}, \mathrm{Q}_{\mathrm{bu}}, \mathrm{Q}_{\mathrm{swu}}$ and $\mathrm{Q}_{\mathrm{u}}$ - theoretical values of the destructive forces (the middle of the span or in console grip; transverse force perceived by concrete along the strip between inclined cross-sections; transverse force perceived by concrete in an inclined section; transverse force perceived by transverse reinforcement in the inclined section; transverse force perceived by concrete and reinforcement in an inclined section, respectively.

method of [5] as a construction of a continuous section. Reliable operation of precast cross beams of the proposed construction with inclined sections can be ensured only if the strength of the monolithic concrete is not lower than the strength of the concrete of the beam part. In calculating the precast cross beams over an inclined strip between oblique sections, from the condition (8.55) [5], the coefficient $\varphi_{b 1}$ in all cases should not exceed 0.2.

\section{Conclusions}

1. The operation of precast cross beams of the proposed construction practically does not differ from the operation of the same beams of a single $\mathrm{T}$-section with a shelf in the stretched zone, provided that the strength of the monolithic concrete is not lower than the strength of the concrete of precast cross beam part.

2. The strength of the normal sections of the tested samples exceeds the theoretical strength determined in accordance with the applicable norms, which makes it possible to calculate the precast cross beams of the proposed design on the action of flexural elements according to the present norms [5] as beams of a single section.

3. Calculation of the crossbeams of the proposed construction according to the inclined sections on the action of transverse forces can be performed according to the present norms [5] as a beam of solid cross section only if the strength of the monolithic concrete is not lower than the strength of the concrete of the precast cross beam (part). In this case, the calculation of the crossbeam along the strip between the inclined sections must be satisfied from the condition (8.55) [5] with the coefficient $\varphi_{b 1}=0.2$.

4. The beams of the proposed construction can be used for the construction of residential and public buildings, and their calculation can be performed according to the present norms for both T-beams of solid T-section taking into account the points mentioned above.

\section{References}

1. S. Kopsha, V. Zaikin, Off shuttering technology forming-the Key to Modernizing Industry and Reducing the Cost of Housing, Technology of Concrete, 11, 29-33 (2013)

2. V. Lukonin, A. Prokopovich, V. Repekto, patent number 73365 (2008)

3. A. Koyankin, V. Mitasov, Experimental studies of the work of the joint of the crossbeam with the column, Vestnik MSSU, 5, 27-35 (2015)

4. In Selyaev, V. Tsyganov, I. Utkin, Combined prefabricated-monolithic ceilings on the basis of prestressed reinforced concrete beams of off shuttering molding, Regional Architecture and Construction, 3, 5-11 (2012)

5. SP 63.13330.2012, Concrete and reinforced concrete structures (2012) 